\title{
A Eficiência dos Serviços Prestados Pelos Operadores Logísticos a Empresa de Plásticos em Joinville - SC
}

\author{
Efficiency of Services Provided by the Company Logistics Operators of Plastics in \\ Joinville - SC
}

William Machado Emiliano ${ }^{1}$; Aline Mellies ${ }^{2}$; Patrícia Borghezan ${ }^{3}$; Rafael Bueno Gretter ${ }^{4}$ Antônio Vitor Machado ${ }^{5}$.

\begin{abstract}
Resumo - Atualmente os serviços de entrega de mercadorias da empresa de plásticos em Joinville são realizados por empresas terceirizadas, denominadas de operadores logísticos. Após a contratação das mesmas é que surgem problemas, como: Extravios de materiais, mudanças de rotas e atrasos de mercadorias. Diante disso, foi considerada a possibilidade de estudar a viabilidade, de melhoraria da eficiência dos serviços prestados pelos operadores logísticos à empresa de plásticos de Joinville; propondo assim, a identificação de medidas que visam à diminuição dos problemas no transporte de mercadorias. $\mathrm{O}$ ambiente empresarial esta cada vez mais competitivo, obrigando as empresas a cumprir os prazos de entrega de mercadorias conforme contratação do serviço. Este trabalho tem como objeto a identificação de falhas dos operadores logísticos de entrega de mercadorias da empresa de plásticos em Joinville - SC, visando a busca por melhorias quanto à satisfação dos clientes, em relação a distribuição de suas mercadorias com um processo qualificado, buscando assim o modelo operacional utilizado e principalmente o motivo pelo qual os mesmos constituem um número elevado de entregas das mercadorias com atraso. A partir do estudo realizado, observou-se que os serviços prestados pelos operadores logísticos terceirizados a empresa de plásticos de Joinville - SC, não estão suprindo as necessidades da empresa contratante, onde as principais falhas dos operadores logísticos foram: ausência de treinamento de funcionários, o uso incorreto de equipamentos logísticos, dificuldades de comunicação por meio digital, atrasos nas entregas, entregas de produtos trocados, perdas e avarias na distribuição de seus produtos e má organização nos armazéns de distribuição. Conclui-se que para atingir um nível de eficiência satisfatório é necessário que os operadores logísticos definam inicialmente suas regiões de atendimento, conforme sua infraestrutura (locais de armazenagem, veículos e equipamentos). Já as transportadoras de pequeno porte deve limitar-se a sua área de atuação, diminuindo sua extensão de atendimento podendo assim se especializar, diminuir seus erros e tornar-se mais competitivo, através de preços e prazos com seus concorrentes.
\end{abstract}

Palavras-chave: Operadores logísticos, eficiência, empresa contratante.

\begin{abstract}
Currently the service delivery of goods of Plastics Company in Joinville are performed by outsourced carriers. Some of these carriers is creating problems, such as misplacement of materials, route changes and delays of goods. Therefore, we considered the possibility of studying the feasibility of improving the efficiency of services provided by logistics operators the plastics company Joinville; thus considering, the identification of measures that they aim at to the reduction of the problems in the transport of merchandises. The business environment is increasingly competitive, leading companies to become more agile in delivering services to their customers. This work has as object the identification of imperfections of the logistic operators of delivery of merchandises of the plastic company in Joinville - SC, aiming at the search for improvements how much to the satisfaction of the customers, in relation the distribution of its merchandises with a qualified process, thus searching operational the model used and mainly the reason of which the same ones constitute a high number of deliveries of the merchandises with delay. From the carried through study, it was observed that the services given for the logistic operators terceirizados the plastic company of Joinville - SC, are not supplying the necessities of the contracting company, where the main imperfections of the logistic operators had been: absence of training of employees, the incorrect logistic equipment use, difficulties of

*autor para correspondência

Recebido para publicação em: 11/12/2012 aprovado em 01/05/2014.

${ }^{1}$ Prof. Logística SENAI -SC - Mestrando Engenharia de Produção - Instituto Superior Tupy / Sociedade Educacional de Santa Catarina - IST/ SOCIESC. CEP - 89206-001. Joinville - SC. E-mail: (william.emiliano@ sc.senai.br);

${ }^{2}$ Técnico em Logística - Serviço Nacional de Aprendizagem Industrial - SENAI. CEP - 89206-001 . Joinville - SC. E-mail: (alinemellies@gmail.com);

${ }^{3}$ Técnico em Logística - Serviço Nacional de Aprendizagem Industrial - SENAI. CEP - 89206-001 . Joinville - SC. E-mail: (patyborghezan@hotmail.com);

${ }^{4}$ Técnico em Logística - Serviço Nacional de Aprendizagem Industrial - SENAI. CEP - 89206-001 . Joinville - SC. E-mail: (rafa_gretter@hotmail.com.br);

5 Engenheiro de Alimentos UFERSA - Universidade Federal Rural do Semi-Àrido - UFERSA. CEP -59780-000. Mossoró - RN (machadoav@ufersa.edu.br)*
\end{abstract}


communication for digital way, delays in the deliveries, deliveries of changed products, losses and you damage in the distribution of its products and harm organization in the distribution warehouses. One concludes that to reach a satisfactory level of efficiency it is necessary that the logistic operators define initially its regions of attendance, as its infrastructure (local of storage, vehicles and equipment). Already the transporters of small transport it must be limited its area of performance, diminishing its extension of attendance thus being able to specialize itself, to diminish its errors and to become more competitive, through prices and stated periods with its competitors.

Keywords: Logistics operators, efficiency, contracting company.

\section{INTRODUÇÃO}

O homem sempre procurou criar instrumentos que atendessem as suas necessidades de sobrevivência, bem-estar e de conforto: habitação, indumentária, adornos, recipientes, instrumentos e armas, bem como o transporte (FARIA, 2013).

O primeiro tipo de transporte terrestre utilizado pelo homem parece ser sido o trenó. Originou-se de tronco de árvore em forma de barco, de prancha, tobogã e patins sobre rodas. Segundo Marconi e Presotto (1986), os primeiros vestígios apareceram no Mesolítico da Finlândia e também nas planícies do Oriente próximo, por volta de 4.000 a.C.

O grande avanço para os transportes terrestres aconteceu com a invenção da roda na Mesopotâmia, antes de 3000 A.C. , talvez derivada do rolete (MARCONI \& PRESOTTO, 1986). De início sólido, pesado e rudimentar, a roda foi aplicada em carros tracionados por animais de grande porte. Com a introdução de usos e raias, ganharam maior velocidade e desempenho.

Os novos veículos, criados à medida que se aperfeiçoava a roda, permitiam melhor locomoção do homem e os antigos caminhos eram transformados em verdadeiras estradas para permitir acesso mais rápido entre cidades. Os romanos foram os grandes peritos em construção de estradas. Começaram em 312 A.C, com a via Ápia. À medida que iam estendendo suas conquistas, iam construindo estradas sempre ligadas ao tronco principal, à via Ápia e os outros caminhos romanos. Possuíam uma rede de $80.000 \mathrm{~km}$ de estradas para o ocidente na Gália, na Espanha e até na Inglaterra e para o oriente construíram estradas na Grécia e na atual Iugoslávia. Era uma extensa rede viária com mais de $350.000 \mathrm{~km}$ de estradas sem pavimentação. Foi na Grécia Antiga que aconteceram os mais intensos congestionamentos. De acordo com os administradores de Atenas, na antiguidade, a largura das ruas de suas cidades era insuficiente e alargá-las seria inútil, uma vez que o volume de tráfego tenderia a crescer. Assim, desde a antiguidade, já estava claro que privilegiar o veículo é um erro (FARIA, 2013).

No império Romano, havia preocupação em resolver os problemas de trânsito. Foi onde surgiram sinalizações, marcos quilométricos, indicadores de sentido e as primeiras regulamentações de tráfego. Os administradores romanos procuraram resolver os problemas do tráfego fazendo uso da lei, através da sua regulamentação.

O modal rodoviário enquanto política de Estado teve origem com o ex-presidente Washington Luís, que discursou ainda como governador de São Paulo em 1920 a célebre frase "Governar é povoar; mas, não se povoa sem se abrir estradas, e de todas as espécies; governar é, pois, fazer estradas"! Enquanto governador de São Paulo, Washington Luís projetou e modernizou estradas no interior do estado e em direção ao Porto de Santos. Ao assumir a presidência, inaugurou em 1928 a Rodovia RioPetrópolis - a primeira rodovia asfaltada do Brasil - e a Rodovia Rio-São Paulo. Criou também a Polícia Rodoviária Federal e um mecanismo para promover o modal rodoviário no Brasil: o Fundo Especial para Construção e Conservação de Estradas de Rodagens Federais.

O governo de Washington Luís foi o ponto inicial para uma mudança total nas rodovias do Brasil. A primeira rodovia pavimentada ligava o Rio de Janeiro a Petrópolis e foi inaugurada em 1928, quando Washington Luís já era presidente. Esse trecho hoje faz parte da BR 040, que liga o Rio de Janeiro a Belo Horizonte. A explosão do desenvolvimento rodoviário aconteceu somente nas décadas de 40 e 50 . O governo de Juscelino Kubitschek adotou com toda a força o lema de Washington Luís (AZEVEDO, 2011).

A fundação de Petrobras e a criação de impostos destinados à construção de estradas também deram impulso às rodovias. A Pesquisa Rodoviária de 2004 feita pela Confederação Nacional dos Transportes, a CNT, apontou que $74,7 \%$ das rodovias apresentaram algum grau de imperfeição. Desse número, 14,6 \% das estradas estão em estado péssimo. O desequilíbrio entre as regiões do país aparece de maneira clara: cerca de um quarto das rodovias do Nordeste estão em péssimo estado de conservação, contra $11 \%$ de rodovias do Sudeste na mesma situação. Para o coordenador da pesquisa CNT, Luiz Sérgio Silveira, a falta de investimentos continuados é o principal fator para este quadro (CNT, 2013).

\section{Empresa de Plástico em Joinville}

Fundada em dezembro de 2004, com sede em um salão alugado no sul da cidade de Joinville - SC, empresa tem seu nome relacionado ao conceito de "Durabilidade e Inovação", combinado com uma visão empreendedora dos seus fundadores que procuram dar soluções completas e conexões de acessórios. 
Devido ao aumento do mercado e excelência operacional indiscutível em fevereiro de 2010 foi inaugurada a sede, localizada em Araquari - SC, reafirmando a qualidade e os diferenciais da marca. Os produtos que são comercializados abrangem acessórios e conexões de plástico de forma rentável destinado às áreas de construção civil, industrial e irrigação atendendo as necessidades do mercado.

Alguns dos produtos são: mangueiras, registros, adaptadores de Caixa D'Água, conexões, purificadores, assento sanitário, torneiras e entre outros. Tem uma distribuição de seus produtos para todo o Brasil, desde o sul ao norte. Conforme a necessidade estrategicamente de terceirizar transportadoras, a empresa de plásticos tem em seu contexto oito transportadoras terceirizadas (EMPRESA DE PLASTICOS EM JOINVILLE, 2013).

\section{Operadores logísticos}

Os desafios dos operadores logísticos estão cada vez maiores. A capacidade de entender as operações que estão gerindo, as necessidades e requisitos dos clientes e atendê-los de maneira consistentes, torna-se cada vez mais fundamental para consolidação dos seus negócios.

De acordo com Botino (2009): Operador logístico é o fornecedor de serviços, especializado em gerenciar e executar todas ou partes das atividades logísticas nas várias fases da cadeia de abastecimento de seus clientes, agregando valor aos produtos e que tenha competência para, no mínimo, prestar simultaneamente serviços nas três atividades básicas de controle de estoques, armazenagem e gestão de transportes.

A importância hoje, no mercado competitivo referente aos serviços dos operadores logísticos é grande, pois os empresários necessitam de uma empresa terceirizada que faça a distribuição de seus produtos para várias localidades com qualidade e rapidez para satisfazer a necessidade de seus clientes (NOVAES, 2001).

\section{Transportadora "A"}

Atuando desde 1985 no transporte de cargas, a Transportadora A alia agilidade, segurança e economia para ter clientes sempre satisfeitos. Como o transporte pode ser um diferencial estratégico nas empresas, o principal objetivo é oferecer vantagens competitivas aos seus clientes. Aplica sua experiência e profissionalismo no transporte de cargas entre o Sul e Sudeste para o Norte e Nordeste do Brasil, atendendo $100 \%$ das cidades destas regiões através de suas unidades.

Além da matriz localizada em Joinville (SC), a Transportadora A possui unidades estrategicamente posicionadas para apoiar sua forte atuação no Norte e Nordeste do País. As suas cargas podem ser fracionadas aonde comportam varias coletas de vários clientes, são transportas em pequenas e grandes quantidades, podem ser realizadas quando as cargas possuem destinos diferentes. E também pode ser carga direta, que é coletado em apenas um local, preenche toda a capacidade do caminhão e é uma ligação direta ao cliente, oferecendo assim agilidade (TRANSPORTADORA A, 2013).

\section{Transportadora "B"}

Fundada em 17 de julho de 1979, o fundador enxergou uma lacuna no mercado regional e uma oportunidade de especialização e crescimento no segmento de cargas fracionadas através da oferta de um serviço de transporte profissional, seguro e organizado que proporcionasse vantagens e facilidades ao cliente em relação aos processos adotados até então.

A Transportadora B tem seu eixo central de atuação nas regiões Sul e Sudeste do Brasil, onde tem presença consolidada. Além da Matriz, localizada em Caxias do Sul - RS, a empresa conta com mais de 80 pontos de distribuição e 17 centralizadoras próprias instaladas em cidades estratégicas dos estados do Rio Grande do Sul, Santa Catarina, Paraná, São Paulo e Minais Gerais, e é referência no transporte de cargas fracionadas. A empresa é especializada e desenvolveu know-how no atendimento dessas regiões. Ela preocupase com a padronização da frota própria e da rede de distribuição, e mantém um controle rígido sobre a manutenção preventiva (TRANSPORTADORA B, 2013).

\section{Transportadora "C"}

Possuem a maior rede em distribuição rodoviária e a maior frota de veículos destinados ao transporte expresso do país. Isto nos torna a maior empresa de transporte expresso do Brasil. A única empresa que possui os modais aéreo e rodoviário, podendo oferecer soluções integradas, que atendem todas as necessidades dos clientes. A Transportadora C, é importante para a empresa de plásticos, aonde distribui seus produtos para cerca de 23 estados no Brasil, apenas não distribui na região do Ceará, Maranhão e Piauí (TRANSPORTADORA C, 2013). Uma transportadora com expansão mundialmente, propondo sempre crescer e assim fornecer as soluções mais confiáveis e eficientes no transporte das amostras e documentos de seus clientes.

As suas cargas podem ser fracionada ou consolidada. A consolidada é aquela que é transportada ao amparo de conhecimento do embarque internacional de carga, emitido pela empresa autorizada ao consolidar a carga, ou seja, agrupar a carga que tenha um só destino.

\section{Terceirização}

A Terceirização faz parte da estratégia da empresa, pois permite focar seus esforços nas atividades principais, reduzindo os custos, obtendo mais velocidade e buscando reduzir ou aumentar a distancia que as separa de seus concorrentes (BERTAGLIA, 2009). Para ser aplicada em algum setor da empresa precisa ser bem estuda, pois a empresa que faz a terceirização precisa ter confiança em seus operadores logísticos terceirizados, pois eles além de entregar os seus produtos irão ter acesso às informações da empresa.

As empresas terceirizam para gerar mais lucros, 
pois elas irão se preocupar mais em produzir o produto, em vez de se preocupar em transportá-lo ou armazena-lo (em alguns casos). Philippe-Pierre et..al. (2000); afirma o seguinte : " há muitos riscos embutidos ao se terceirizar a logística[...] Risco comercial: a imagem do fabricante irá inevitavelmente ser ligada à de uma empresa de serviços." Elas terceirizam seus serviços como uma forma de agilizar ou de obter mais qualidade na entrega de seus materiais, mas muitos operadores logísticos não estão conseguindo suprir a necessidade de seus clientes como o caso da Durín, onde seus terceiros não cumprem os prazos estipulados, prejudicando assim todo o planejamento logístico realizado, comprometendo a relação entre empresa e cliente.

\section{Nível de Serviço}

Também conhecido como nível de atendimento ou grau de atendimento, é descrito por Jacobsen (2006, p. 55) como "[...] a relação entre quantidade atendida e a quantidade solicitada". Ou seja, é a associação dos pedidos pretendidos com os pedidos efetuados, e saber se os pedidos estão sendo entregues.

Martins et. al. (2001, p. 137); define nível de serviço como " uma medida de qualidade. É formado por um conjunto de elementos quantitativos e representativos da qualidade do serviço prestado, passível de graduação em uma escala." O nível de serviço é uma medida qualitativa, mas que precisa de vários fatores quantitativos e figurativos de qualidade de serviço para obter os resultados da empresa.

O conceito de nível de serviço, segundo Martins et. al. (2001); “O transporte eficiente deve ser capaz de respeitar os prazos de entrega, com o objetivo de reduzir custos logísticos. Produtos que são entregues antes ou após a data programada podem implicar elevação dos custos, por causa da necessidade de armazenamento e da redefinição da programação de produção das empresas".

O transporte para ser eficiente necessariamente não precisa chegar antes na empresa compradora e sim na data combinada, pois isso acarretaria vários problemas à empresa, pois um planejamento para o recebimento da mesma. Durante a realização do transporte, diversos inconvenientes podem ocorrer com a carga, causando danos ao serviço oferecido pela empresa aos seus clientes.

De acordo com Alvarenga e Novaes (2000), "os principais fatores que geram um nível de serviço de determinado sistema são prazo de entrega, avarias causadas na carga, extravios durante a operação e reclamações diversas." Os operadores logísticos terceirizados da empresa de plástico em Joinville não estão satisfazendo os clientes da empresa, não cumprem esses fatores para geram um bom nível de serviço, pois nesta relação o prejudicado é a empresa e seus clientes que não ficam satisfeitos com os serviços dos operadores logísticos terceirizados.

\section{Avarias e perdas}

As perdas e avarias acontecem com maior frequência nas operações de carga e descarga de mercadorias. Para se evitar que estas ocorram com tamanha frequência recomenda-se utilizar veículos adequados para o transporte de cada mercadoria, unitizar a carga sempre que possível, treinar o pessoal e usar equipamentos apropriados. Infelizmente nem sempre esses cuidados todos são suficientes para se evitar a perda de cargas. Outro fator que facilita a perda de mercadoria é a falta de organização das transportadoras, e equipe logística, afinal é muito comum se perder mercadorias dentro das próprias transportadoras e só se encontrar em média de 15 ou 20 dias depois do prazo de entrega.

Apesar de relativamente seguro, o transporte rodoviário não está livre de avarias e extravios. E nas pontas, nas operações de carga e descarga, que esse tipo de problema se apresenta com maior gravidade, em razão da manipulação inevitável da mercadoria. Há formas de reduzir significativamente as avarias. Entre outros, utilizar veículos adequados, que facilitem as operações de carga e descarga: unitizar a carga sempre que possível (pallets, contêineres); melhorar a capacitação do pessoal; usar equipamentos apropriados e racionalizar o layout do armazém (NOVAIS, 2000).

Para uma empresa diminuir extravio e avarias no transporte, precisa de equipamentos certos para cada tipo de atividade efetuada, e gerar menos problemas logísticos na organização.

\section{MATERIAL E MÉTODOS}

\section{METODOLOGIA}

\section{Visita Técnica}

Neste trabalho foi realizada uma visita na empresa de Plásticos de Joinville, com objetivo de conhecer o processo de expedição das mercadorias.

\section{Análise de informações}

Com a autorização da empresa para realização do estudo, foram analisadas informações de três operadores logísticos, e foram denominadas de transportadoras A, B e C, e para material de estudo foram disponibilizados planilhas, gráficos e relatórios da empresa de plásticos em Joinville.

\section{Análises estatísticas}

Através dos dados obtidos, foram comparados os números dos três operadores logísticos, visando a busca pela operadora que possua a melhor eficiência na prestação de serviço.

\section{RESULTADOS E DISCUSÕES}

A análise dos dados teve início, com a disponibilização de planilhas, gráficos e relatórios da empresa de plásticos em Joinville, com isso foi possível analisar os números de cada operação e a identificação dos 
principais problemas, facilitando esse processo e não sendo necessária a realização de uma pesquisa com a utilização de questionário.

Para NOVAES (2001, p. 371), "Medir a eficiência e monitorar permanentemente o desempenho das empresas e subsistemas da cadeia de suprimento passam a serem atividades de grande importância no atual mercado consumidor". Medindo a eficiência de cada operador logístico é de grande importância, pois assim é possível verificar quais os problemas detectados e analisar como solucionar para que as mercadorias sejam entregues durante o prazo estipulado e consequentemente satisfazendo os clientes da empresa.

A transportadora A abrange a região nordeste do estado, onde está ocorrendo o maior numero de problemas logísticos, pois além de ser uma região com um desenvolvimento tecnológico baixo, também está ocorrendo divergências de informações entre a empresa e a transportadora.

A transportadora $\mathrm{B}$ abrange a região de Minas Gerais e o Sul do Brasil, são casos isolados de atrasos ou extravios.

A transportadora $\mathrm{C}$ que é responsável por cerca de $70 \%$ de todas as entregas de mercadorias da empresa de plástico em Joinville, a eficiência é relativamente diferenciada por cada região ou estado.

\section{Análise de Dados dos Operadores Logísticos}

A transportadora A tem um grande problema operacional por abranger a região nordeste, aonde é consideradas uma das regiões com maior números de ocorrências. Conforme estudo dos dados obtidos para o estado do Ceará durante o período de janeiro á abril de 2013, houve uma queda da eficiência nas entregas das mercadorias, pois existe um grande numero de entregas atrasadas pelo motivo do pagamento de imposto antecipado. O pagamento do imposto antecipado é obrigatório para os clientes de estados que não tem substituição tributária e querem comprar produtos de outros estados. Há um processo de envio dos boletos para os clientes e um prazo de vencimento, o qual a cada prazo de vencimento não cumprido é gerado outro imposto antecipado (DAE). Quanto mais rápido o cliente recebe o boleto e efetua o pagamento, mais rápido o processo de entrega será realizado.

Porém, está ocorrendo casos em que o cliente efetua o pagamento com a agilidade, mas a transportadora não libera as mercadorias com a mesma rapidez. Cada mercadoria que é entregue com atraso o cliente tem direito a prorrogação de seus boletos do pedido feito, gerando mais custo para a transportadora e para a empresa.

Figura1 - Motivos de Atrasos Transportadora

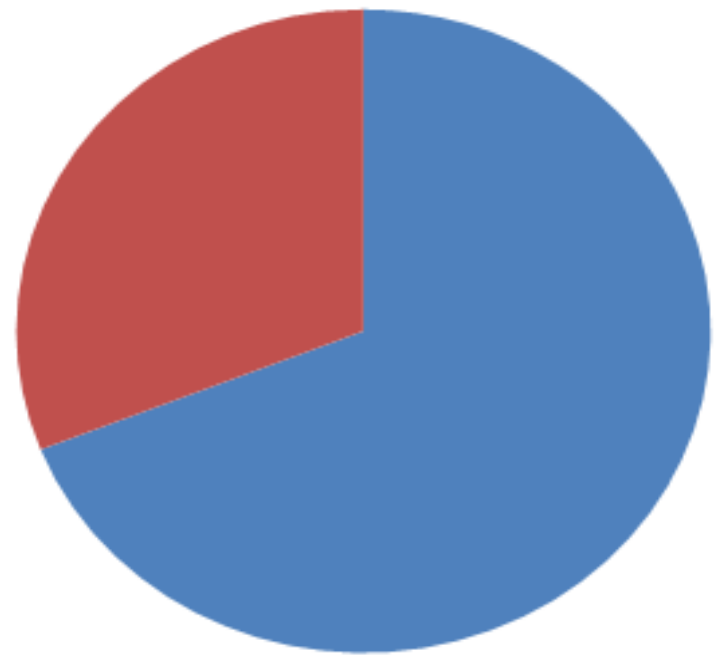

Im posto antecipado

Problema operacional da transportadora

Fonte: Empresa de Plásticos (2013)

Conforme Tabela 1, quando se analisa a transportadora B verifica-se que a eficiência total da mesma no período de Janeiro a abril de 2013 é vista como suficiente, pois teve um resultado de $86,40 \%$ de eficiência de 147 mercadorias entregues, apenas 20 ocorrerão problemas com atrasos na entrega. A transportadora no período de janeiro entregou 34 mercadorias, destas 28 ocorreram antes ou no prazo previsto e 6 fora do prazo. Já em fevereiro constatou que teve uma melhora em sua eficiência de $7 \%$, sendo que de 38 mercadorias, 33 foram entregues no prazo e 5 fora do prazo. Analisando os períodos de janeiro a abril Tabela 2 a transportadora B 
aumentou seu índices de eficiência diminuindo o numero de entregas com atrasos, no período de abril de 35

mercadorias entregues, 4 foram entregues com atraso.

Tabela 1 - Índice de Eficiência total transportadora B.

\begin{tabular}{ccc}
\hline Entregas & $\mathbf{N}^{\mathbf{0}}$ entregas & Eficiência \\
\hline Antes do prazo & 64 & $44,2 \%$ \\
\hline No prazo & 63 & $42,2 \%$ \\
Fora do prazo & 20 & $13,6 \%$ \\
\hline Total de entregas & 147 & $100 \%$ \\
\hline
\end{tabular}

Fonte: Empresa de Plástico em Joinville (2013)

Tabela 2 - Índice de Eficiência no período Janeiro á Abril de 2013.

\begin{tabular}{|c|c|c|c|c|c|}
\hline Prazo & Janeiro & Fevereiro & Março & Abril & Total \\
\hline No prazo & 28 & 33 & 35 & 31 & 127 \\
\hline Fora prazo & 6 & 5 & 5 & 4 & 20 \\
\hline$(\%)$ & 21 & 15 & 14 & 13 & 147 \\
\hline
\end{tabular}

Fonte: Empresa de Plástico em Joinville (2013)

Conforme Anexo 6, durante o período de janeiro a transportadora $\mathrm{C}$ teve um índice de eficiência muito abaixo do esperado para os estados de São Paulo e Distrito Federal. No estado de São Paulo o índice de eficiência foi de $75,74 \%$, de 169 mercadorias entregues, 41 mercadorias foram entregues fora do prazo estipulado.

Analisando a região do Distrito Federal o índice de eficiência foi de $81,25 \%$, sendo este considerado baixo por ser a capital do país.

Conforme Anexo 7, durante o período de fevereiro a transportadora, em estudo, sofre uma grande queda em seus índices de eficiências nos estados de Acre, Bahia, Espírito Santo, Goiás, Mato Grosso e São Paulo.

$\mathrm{O}$ estudo em relação ao estado do Acre e o da Bahia mostra o seguinte cenário: No Acre, houve uma em decadência em seus índices de eficiências de 22,22\% em comparação ao mês anterior, o índices de eficiências do mês em estudo relatado foi de $66,67 \%$, de 15 mercadorias entregues, 5 foram entregues com atraso. Já na Bahia a eficiência da transportadora caiu de $18,97 \%$. A eficiência no mês de janeiro (anexo 6) foi de $87,79 \%$ e no mês de fevereiro o índices de eficiências foi de $68,82 \%$, de 340 mercadorias distribuídas 97 foram entregues fora do prazo estipulado.

Quando se analisa o estado do Espírito Santo percebe-se uma queda dos índices de eficiências de $26,0 \%$. Para o mês de janeiro o índice de eficiências foi de $87,27 \%$ (Tabela 3), já no mês de fevereiro caiu para $61,27 \%$, de 142 mercadorias distribuídas 53 foram entregues depois do prazo estipulado. No estado de Goiás ocorreu o oposto, onde o índice de eficiência no mês de janeiro foi de 94,29\% considerado um índice excelente (tabela 3) , mas em comparação ao mês de fevereiro houve uma queda de $17,12 \%$ chegando ao índice de
$77,17 \%$, de 92 mercadorias distribuídas neste periodo, 19 mercadorias foram entregues fora do prazo estimulado.

A eficiência de janeiro (tabela 3), no Mato Grosso, foi abaixo do esperado cerca de $75 \%$ mas em comparação com o mês de fevereiro (Tabela 4) que foi de $55,51 \%$ houve uma decadência de $19,49 \%$, de 90 mercadorias distribuídas aos clientes finais, 30 foram entregues fora prazo de entrega estipulado.

No Estado de São Paulo a transportadora C apresentou uma queda nos índices eficiências de 13,7\% em comparação ao mês anterior, de 461 mercadorias entregues aos clientes finais 170 foram entregues fora do prazo estipulado.

Conforme Tabela 5, no mês de março a mesma apresentou uma elevação em seus índices de eficiências, apenas os Estados de São Paulo e Acre apresentaram índices de eficiência abaixa do esperado, Para os estados de São Paulo de 440 mercadorias entregues, 103 foram entregues fora do prazo estipulado. Já no Acre de 16 mercadorias entregues 9 foram com atrasos.

A transportadora $\mathrm{C}$ no mês de abril, conforme Tabela 6, teve uma ótima eficiência em quase todos estados, já em São Paulo durante o período de janeiro, fevereiro e março de 2013, os índices de eficiências apresentaram uma queda em seus índices, no período de abril o percentual de eficiência aumentou de 12,97\% em comparação com aos dados do mês anterior. O estado de Roraima foi o que apresentou o menor percentual analisado entre todos analisados, com índices de eficiência de $50 \%$. 
TABELA 3 - Embarques transportadora C mês de Janeiro.

\begin{tabular}{ccc}
\hline Estados & Qtd & \% EFIC \\
\hline AC & 9 & 88,89 \\
AM & 3 & 33,33 \\
BA & 131 & 87,79 \\
DF & 16 & 81,25 \\
ES & 89 & 84,27 \\
GO & 35 & 94,29 \\
MS & 26 & 88,46 \\
MT & 28 & 75,00 \\
PA & 57 & 80,7 \\
PR & 147 & 88,44 \\
RJ & 4 & 50,00 \\
RO & 23 & 91,3 \\
RR & 3 & 66,67 \\
RS & 108 & 86,11 \\
SC & 17 & 82,35 \\
SP & 169 & 75,74 \\
TO & 20 & 80,00 \\
\hline
\end{tabular}

Fonte: Empresa de Plástico em Joinville (2013)

TABELA 5 - Embarques transportadora C mês de março/2013

\begin{tabular}{ccc}
\hline Estados & Qtd & \% EFIC \\
\hline AC & 16 & 37,50 \\
BA & 290 & 85,17 \\
ES & 134 & 88,81 \\
MS & 37 & 64,86 \\
MT & 68 & 85,29 \\
PA & 127 & 96,06 \\
PR & 260 & 85,77 \\
RO & 52 & 71,15 \\
RS & 199 & 91,46 \\
SC & 39 & 82,05 \\
SP & 440 & 76,14 \\
\hline
\end{tabular}

Fonte: Empresa de Plástico em Joinville (2013)
TABELA 4 - Embarques transportadora C mês de Fevereiro/2013

\begin{tabular}{ccc}
\hline Estados & Qtd & \% EFIC \\
\hline AC & 15 & 66,67 \\
AM & 10 & 50,00 \\
AP & 13 & 69,23 \\
BA & 340 & 68,82 \\
DF & 27 & 92,59 \\
ES & 142 & 61,27 \\
GO & 142 & 77,17 \\
MS & 31 & 61,29 \\
MT & 90 & 51,11 \\
PA & 163 & 89,57 \\
PR & 371 & 54,72 \\
RO & 69 & 73,91 \\
RR & 10 & 60,00 \\
RS & 231 & 84,85 \\
SP & 461 & 62,04 \\
TO & 59 & 66,10 \\
\hline Fonte: Empresa de Plástico em Joinville (2013)
\end{tabular}

TABELA 6 - Embarques transportadora C mês de Abril/2013

\begin{tabular}{ccc}
\hline Estados & Qtd & \% EFIC \\
\hline AC & 10 & 90 \\
AP & 13 & 92,31 \\
BA & 298 & 89,93 \\
DF & 30 & 90 \\
ES & 140 & 93,57 \\
GO & 114 & 90 \\
MS & 37 & 97,37 \\
MT & 68 & 95,35 \\
PA & 127 & 88,31 \\
PE & 2 & 94,29 \\
PR & 151 & 87,42 \\
RO & 59 & 50 \\
RS & 267 & 94,76 \\
SC & 45 & 93,33 \\
SP & 459 & 89,11 \\
TO & 50 & 90 \\
Fonte: Empresa de Plástico em Joinville (2013)
\end{tabular}


Conforme o estudo realizado a região nordeste, particularmente no estado do Ceará que abrange o maior número de problemas ocorridos em relação a entregas com atrasos. Pois este estado não possui o imposto de substituição tributária, assim, hà necessidade de seguir um processo de pagamento do imposto antecipado, sendo encaminhado pelas empresas fornecedoras a seus clientes por meio de um operador logístico.

Porém, alguns clientes do estado do Ceará não possuem tecnologia suficiente para fazer a operação por meio da internet, dificultando assim o processo com seus fornecedores, tornando difícil para o cliente efetuar o pagamento do imposto antecipado e quando efetua o pagamento, a transportadora comete alguns erros operacionais, ultrapassando os 7 dias após o pagamento do imposto antecipado para a liberação da mercadoria. Com a liberação, a mercadoria é despachada para a entrega ao cliente final e assim, consequentemente é entregue fora do prazo. Já a transportadora B que distribui as mercadorias da empresa para a região sul do país, existem casos isolados decorrentes de atrasos de mercadorias superior a 24 horas.

A transportadora $\mathrm{C}$ sendo a principal transportadora da empresa de plástica em Joinville, distribuindo as mercadorias da empresa para 19 estados brasileiros, durante certo período, houve índices elevados de atrasos nas regiões de São Paulo e do Norte do país, decorrendo assim, um baixo no nível de eficiência operacionais, ultrapassando os 7 dias após o pagamento do imposto antecipado para a liberação da mercadoria. Com a liberação, a mercadoria é despachada para a entrega ao cliente final e assim, consequentemente é entregue fora do prazo. Já a transportadora B que distribui as mercadorias da empresa para a região sul do país, existem casos isolados decorrentes de atrasos de mercadorias superior a 24 horas.

\section{CONCLUSÕES}

De acordo com os dados analisados, podemos concluir que:

As principais falhas dos operadores logísticos de entrega de mercadorias da empresa de plásticos em Joinville foram: Ausência de treinamento de funcionários, o uso incorreto de equipamentos logísticos, dificuldades de comunicação por meio digital, atrasos nas entregas, entregas de produtos trocados, perdas e avarias na distribuição de seus produtos e má organização nos armazéns de distribuição.

$\mathrm{Na}$ comparação entre os três operadores logísticos, os índices de eficiência estão diretamente relacionados com as regiões atendidas, entre os periodos avaliados todos apresentaram um aumento significativo dos índices de eficiência.

Conclui-se que para atingir um nível de eficiência satisfatório é necessário que os operadores logísticos definam inicialmente suas regiões de atendimento, conforme sua infraestrutura (locais de armazenagem, veículos e equipamentos). Já as transportadoras de pequeno porte deve limitar-se a sua área de atuação, diminuindo sua extensão de atendimento podendo assim se especializar, diminuir seus erros e tornar-se mais competitivo, através de preços e prazos com seus concorrentes.

\section{REFERÊNCIAS BIBLIOGRÁFICAS}

ALVARENGA, A. C. e NOVAES, A. G . L.ogística aplicada. 3. Ed. São Paulo: Edgard Blücher, 2000.

ALVEZ DINIZ, E. L. Qualidade no serviço logístico. Disponível em: http://www.fumec.br/anexos/cursos/mestrado/dissertacoes /resumo/2010/erica_leonor_alves_leroy_diniz.pdf. Acesso em 25 de março de 2013.

ARAÚJO, J. G. Transporte rodoviário no Brasil. Disponível

em: www.portogente.com.br/portopedia/Transporte_Rodoviari o/. Acesso em 30 de abril de 2013.

AZEVEDO, R. P. O Aumento da Demanda de Passageiros no Sistema Ferroviário na Região da Grande São Paulo e a Relação com a utilização do Bilhete Único: Estudo de caso Estação Guaianases da Companhia Paulista de Trens Metropolitanos (CPTM). 2011. Disponível em: <http://www.fateczl.edu.br/cariboost_files/Rodrigo_20Pir es_20de_20Azevedo.pdf $>$. Acesso em: 11 out. 2013.

BERTAGLIA, Paulo Roberto. Logística e gerenciamento da cadeia de abastecimento. São Paulo: Editora Saraiva, 2009.

BOTTINO, A. A. Viabilidade de Utilização de Operadores Logísticos Civis pela Força Terrestre, na Execução das Funções Logísticas Transporte e Suprimento, em Operações. Disponível em: <www.eceme.ensino.eb.br>. Acesso em: 04 nov. 2013.

CAIXETA-FILHO, J. V.; MARTINS, R. S. Gestão Logística no Transporte de Cargas. São Paulo (SP): Atlas, c2001. 296 p. ISBN

CNT. Pesquisa Rodoviária 2004. Disponível em: <http://www.cnt.org.br/Paginas/index.aspx>. Acesso em: 04 out. 2013

DORNIER, P. P. et al. Logística e operações globais: texto e casos. Editora: São Paulo: Atlas, 2000

DURÍN ACESSÓRIOS E CONEXÕES, Empresa. Empresa Durín. Disponível em: 
http://www.durin.com.br/. Acesso em 10 de março de 2013.

FARIA, E. O. História dos transportes terrestres no mundo. Disponível em:

$<$ http://www.transitocomvida.ufrj.br/HistoriaDoTransitoN oMundo.asp>. Acesso em: 10 jul. 2013.

FLEURY, P. F. Eficiência dos transportes logísticos. Disponível

em: http://www.scielo.br/pdf/gp/v4n2/a09v4n2.pdf. Acesso em 10 de abril de 2013.

FUN GHI SU, A. Satisfação no serviço logístico. Disponível em: http://www.msconsulting.com.br/wpcontent/themes/wpremix2/arquivos/o-impacto-do-nivelde-servico-logistico.pdf. Acesso em 27 de março de 2013.

GRONROOS, C. Marketing gerenciamento e serviços. Rio de janeiro: Editora Campus LTDA, 1995.

JACOBSEN, M. Logística Empresarial. 2. Ed. Itajaí: Univale, 2006.

KICH GONTIJO, F. E. Eficiência dos transportes logísticos. Disponível em: http://www.excelenciaemgestao.org/Portals/2/documents/ cneg6/anais/T10_0266_1258.pdf. Acesso em 8 de abril de 2013.

LÁZARO DA SILVA, J. C. Por que o Brasil investiu em rodovias. Disponível em: www.brasilescola.com/geografia/porque-brasil-adotouutilização-das-rodovias-ao-inves-.htm. Acesso em 30 de abril de 2013.

LEVY, H. O Custo da Não Qualidade nas Disponível em: http://www.herosconsultoria.com.br/conteudo.php?tipo=i \&codigo_con=449. Acesso em 15 de maio de 2013.

MARCONI, M. A. \& PRESOTTO, Z. M. N (1986) Antropologia: uma introdução. $3^{\mathrm{a}}$. ed. São Paulo. Atlas.

MANN, Transportadora. Transportadora Mann. Disponível em: www.transmann.com.br. Acesso em 20 de abril de 2013.

NOVAES, A. G. Logística e gerenciamento da cadeia de distribuição: estratégia, operação e avaliação. Rio de Janeiro: Campus, 2001.

PESSOA, N. Perdas e avarias. Disponível em: http://www.administradores.com.br/produçãoacademica/avarias-na-logistica-de-distribuição-fisicaestudo-de-caso-na-empresa-ohara-transporte-logistica-/. Acesso em 27 de abril de 2013.
SILVA, M. R. Transporte de carga parcelada. Disponível em: http://sites.poli.usp.br/ptr/ptr/docentes/cbcunha/files/Disse rtFinal_MarcosRobertoSilva.pdf. Acesso em 25 de março de 2013.

TNT, Transportadora. Transportadora TNT. Disponível em: http://www.tnt.com/. Acesso em 20 de abril de 2013.

TONTINI, G.; ZANCHETT, R. Satisfação nos serviços logísticos. Disponível em: http://www.scielo.br/pdf/gp/v17n4/a13v17n4.pdf. Acesso em 20 de março de 2013. 